\title{
Hemodialysis Leukopenia
}

\author{
PULMONARY VASCULAR LEUKOSTASIS RESULTING FROM \\ COMPLEMENT ACTIVATION BY DIALYZER \\ CELLOPHANE MEMBRANES
}

\author{
Philip R. Craddock, Jorg Fehr, Agustin P. Dalmasso, Kenneth L. Brigham, \\ and HARRY S. JACOB \\ From the Hematology Section, Department of Medicine, University of Minnesota, Minneapolis, \\ Minnesota 55455; the Clinical Laboratory Section, Laboratory Service, Veterans Administration \\ Hospital, Minneapolis, Minnesota 55417; the Pulmonary Section, Department of Medicine, \\ Vanderbilt University, Nashville, Tennessee 37213
}

A B S T R A C T Acute leukopenia occurs in all patients during the first hour of hemodialysis with cellophanemembrane equipment. This transient cytopenia specifically involves granulocytes and monocytes, cells which share plasma membrane reactivity towards activated complement components. The present studies document that complement is activated during exposure of plasma to dialyzer cellophane, and that upon reinfusion of this plasma into the venous circulation, granulocyte and monocyte entrapment in the pulmonary vasculature is induced. During early dialysis, conversion of both $\mathrm{C} 3$ and factor B can be demonstrated in plasma as it leaves the dialyzer. Moreover, simple incubation of human plasma with dialyzer cellophane causes conversion of C3 and factor B, accompanied by depletion of total hemolytic complement and C3 but sparing of hemolytic C1. Reinfusion of autologous, cellophane-incubated plasma into rabbits produces selective granulocytopenia and monocytopenia identical to that seen in dialyzed patients. Lungs from such animals reveal striking pulmonary vessel engorgement with granulo-

This work was presented in part at the 67th Annual Meeting of The American Society for Clinical Investigation, May 1975 Atlantic City, N. J., 1975. Clin. Res. 23: 402A. (Abstr.)

Dr. Brigham is an Established Investigator of the American Heart Association.

Dr. Fehr's present address is Kantonsspital Zurich, Department fur Innere Medizine der Universitat, Medizinische Klinik, CH-8091, Zurich, Switzerland. Address reprint requests to Dr. Craddock, Department of Medicine, University of Minnesota, Minneapolis, Minn. 55455.

Received for publication 31 March 1976 and in revised form 25 January 1977. cytes. The activated complement component(s) responsible for leukostasis has an approximate molecular weight of 7,000-20,000 daltons. Since it is generated in C2-deficient plasma and is associated with factor B conversion, it is suggested that activation of complement by dialysis is predominantly through the alternative pathway.

\section{INTRODUCTION}

Profound leukopenia limited to granulocytes and monocytes occurs in all patients during the first $2 \mathrm{~h}$ of hemodialysis (1-3). Evidence from studies in dialyzed dogs suggests that this leukopenia is the result of cell sequestration within the pulmonary vasculature (4); the sequestration is transient and is followed by return of the trapped leukocytes to the circulation within 1-2 h, accompanied by a small cohort of younger cells freshly released from the bone marrow storage pool (3). This cytopenia has been documented to occur with all types of cellophane-membrane dialyzers (2), but not with those containing other membranes such as polysulfone (5). Furthermore, if heparinized human plasma is exposed to dialyzer cellophane and then reinfused into humans, it reproduces the acute, transient, and selective leukopenia of hemodialysis (6). These data implied that one or more plasma factors which are activated by contact with dialyzer cellophane induce pulmonary leukostasis and the consequent leukopenia. The selective involvement of granulocytes and monocytes, cells known to be reactive to activated complement (C) components, suggested to us that $C$ components might be the plasma factors involved. Indeed, 
C5a, C $\overline{567}$, and perhaps C3a potently react with granulocytes and monocytes, particularly as chemotaxins (7-9). Moreover, C5a alters granulocyte surface charge (10), and induces release of lysosomal enzymes from cytochalasin B-treated granulocytes (11). That cellophane, a polysaccharide, might activate C components seemed not unlikely since numerous other polysaccharides, notably zymosan, inulin, and endotoxins, are capable of inducing complement activation, predominantly via the alternative pathway $(12,13)$. The present studies demonstrate that dialyzer cellophane is, in fact, capable of inducing plasma complement activation, and that one or more of the low molecular weight-activated components so produced, is probably responsible for the pulmonary leukostasis and peripheral leukopenia seen in dialyzed patients.

\section{METHODS}

Patient studies. Adult patients undergoing routine hemodialysis at the University of Minnesota Hospitals were studied. Dialysis was performed for 4-6 h with disposable single-use, parallel-plate cuprophane equipment (Gambro Lundia, A. B. Gambro, Lund, Sweden.). Circulatory access was gained with Quinton-Scribner (14) or Buselmeier (15) shunts, or arteriovenous fistulae (16). Anticoagulation within the dialyzer was achieved with low dose heparin infused into its afferent blood line (17). Blood for automated cells counts (Coulter model S, Coulter Electronics Inc., Hialeah, Fla.), leukocyte differential counts, and preparation of serum for lysozyme assay, was drawn from this afferent line, proximal to the point of heparin infusion.

Serum hemolytic complement assays were performed utilizing the following buffers and reagents: gelatin-Veronal buffer (GVB) ${ }^{1}$ (18), GVB containing $0.15 \mathrm{mM} \mathrm{Ca}^{2+}$ and 0.5 $\mathrm{mM} \mathrm{Mg}^{2+}(\mathrm{GVBM})(18,19)$, glucose-gelatin-Veronal buffer containing $0.3 \mathrm{mM} \mathrm{Ca}{ }^{2+}$ and $1.0 \mathrm{mM} \mathrm{Mg}{ }^{2+}$ (GGVBM) (19), and GVB containing $10 \mathrm{mM}$ EDTA (GVB/EDTA) (19). C/EDTA was prepared by mixing $0.5 \mathrm{ml}$ of guinea pig serum (Cordis Laboratories, Miami, Fla.), $2.5 \mathrm{ml}$ of a $0.2 \mathrm{M}$ aqueous EDTA solution, and $9.5 \mathrm{ml} \mathrm{GVB}$. Ci was prepared by dialysis at $4^{\circ} \mathrm{C}$ of $10 \mathrm{ml}$ guinea pig serum against phosphate-buffered saline (PBS) $(\mu \mathrm{m}, 0.04)$ containing 0.3 $\mathrm{mM} \mathrm{Ca}{ }^{2+}$ and $1.0 \mathrm{mM} \mathrm{Mg}^{2+}$ at $\mathrm{pH} 7.5$ (PBSM) for $4 \mathrm{~h}$, with hourly changes of the l-liter bath. The dialyzed serum was centrifuged at $10,000 \mathrm{~g}$ for $45 \mathrm{~min}$ at $9^{\circ} \mathrm{C}$ and the precipitate was then dissolved in $20 \mathrm{ml}$ PBSM. The remaining coarse precipitate was removed from this $\mathrm{Cl}$ preparation by further centrifugation at $2,000 \mathrm{~g}$ for $10 \mathrm{~min}$ at $0^{\circ} \mathrm{C}$. The hemolytic activity of the $\mathrm{Cl}$ preparation was measured as site-forming units per milliliter using EAC4 and guinea pig C2 (Cordis Laboratories) in GGVBM. After a 15-min incubation at $30^{\circ} \mathrm{C}$, hemolysis was induced by the addition of excess C/EDTA $(18,20)$. The activity of various $\mathrm{Cl}$ preparations was of the range $10^{13}-10^{14}$ site-forming units/ml. Human C5 through C9 were obtained commercially

\footnotetext{
${ }^{1}$ Abbreviations used in this paper: EA, antibody-coated sheep erythrocytes; GGVBM, glucose-gelatin-Veronal buffer containing $0.3 \mathrm{mM} \mathrm{Ca}{ }^{2+}$ and $1.0 \mathrm{mM} \mathrm{Mg}^{2+}$; GVB, gelatin-Veronal buffer; GVBM, GVB containing $0.15 \mathrm{mM}$ $\mathrm{Ca}^{2+}$ and $0.5 \mathrm{mM} \mathrm{Mg}^{2+}$; $\mathrm{PBS}$, phosphate-buffered saline; PBSM, PBS containing $0.3 \mathrm{mM} \mathrm{Ca}{ }^{2+}$ and $1.0 \mathrm{mM} \mathrm{Mg}^{2+}$.
}

(Cordis Laboratories). Sheep erythrocytes (E) were washed in isotonic saline, GVB/EDTA, and GVBM and stored in GVB containing $250 \mathrm{U} / \mathrm{ml}$ penicillin and $250 \mu \mathrm{g} / \mathrm{ml}$ streptomycin (Gibco Diagnostics, Chagrin Falls, Ohio) at a cell count of $10 \% \mathrm{ml}$ (19). Antibody-coated E (EA) were prepared by the addition of heated rabbit antiserum (BBL hemolysin, BioQuest, BBL Falcon Products, Becton, Dickinson \& Co., Cockeysville, Md.) diluted 1/800 in GVB/EDTA, to an equal volume of washed $E$ at a concentration of $10^{9}$ cells/ml in GVB/EDTA (19). After two 30-min incubations at $37^{\circ}$ and $0^{\circ} \mathrm{C}$, respectively, EA were serially washed in GVB/EDTA and GGVBM and stored at a concentration of $10^{9}$ cells $/ \mathrm{ml}$ in GGVBM/penicillin/streptomycin. EACl were prepared by the incubation of $E A$ with sufficient $\mathrm{Cl}$ to provide 400 site-forming units/cell for $10 \mathrm{~min}$ at $0^{\circ} \mathrm{C}$. EAC1,4 for preparation of EAC4 were made by incubation of $30 \mathrm{ml} \mathrm{EAC1}$, suspended at $5 \times 10^{8}$ cells $/ \mathrm{ml}$ in GGVBM, with $30 \mathrm{ml}$ normal human serum (diluted and preincubated for $15 \mathrm{~min}$ at $37^{\circ} \mathrm{C}$ with $270 \mathrm{ml}$ GVB/EDTA), for $15 \mathrm{~min}$ at $0^{\circ} \mathrm{C}$. EAC4 were prepared by a triple washing of these $\mathrm{EAC} 1,4$ in GVB/EDTA and a single washing in GGVBM, and were stored at $10^{9} / \mathrm{ml}$ in GGVBM/penicillin/streptomycin. EACl,4 for assays were prepared by incubation of these EAC4 with sufficient $\mathrm{Cl}$ to provide 400 site-forming units/cell for $1 \mathrm{~h}$ at $0^{\circ} \mathrm{C}$, washed, and stored at $10^{9}$ cells $/ \mathrm{ml}$ in GGVBM/penicillin/streptomycin. Total serum hemolytic complement levels were determined by the method of Kabat and Mayer (18), C1 levels by the method described above for $\mathrm{C} 1$ preparation (20), and C3 levels by the addition to EAC1,4 of guinea pig $\mathrm{C} 2$ and excess of the human complement components C5 through C9 (Cordis Laboratories) (20). The heparin content of all sera studied was insufficient to inhibit assay reactivity, and all sera were stored at $-70^{\circ} \mathrm{C}$ before assay.

Sera from dialyzed patients for immunoelectrophoretic analysis of C3 and factor B were prepared from blood samples drawn simultaneously from the afferent and efferent dialyzer lines. Immunoelectrophoresis of these sera was carried out in $1.5 \%$ agarose containing $5 \mathrm{mM}$ EDTA in Veronal buffer, $\mathrm{pH} 8.6$, and $\mu \mathrm{m} \mathrm{0.05}$. Anti-human C3 was prepared by immunization of rabbits with purified human C3 (21), and anti-human factor B purchased commercially (Behring Diagnostics, American Hoechst Corp., Sommerville, N. J.).

Experiments with human plasma in vitro. Venous blood from normal adults of blood group $\mathrm{AB}$ was drawn into a cold plastic syringe and immediately centrifuged at $12,000 \mathrm{~g}$ for $10 \mathrm{~min}$ at $4^{\circ} \mathrm{C}$. Heparin was added to the cold plasma to a concentration of $1 \mathrm{U} / \mathrm{ml}$, a level which approximates that achieved within dialyzer circuits (17). The dialyzer system was duplicated in vitro by incubation of dialyzer cellophane with this plasma, at a ratio of $20 \mathrm{~cm}^{2}$ cellophane/ml plasma, for $30-60 \mathrm{~min}$ at $37^{\circ} \mathrm{C}$ in a revolving, sterile polystyrene tube. A positive control for plasma complement activation was provided by the use of zymosan. Zymosan (ICN Pharmaceuticals Inc., Lite Sciences Group, Cleveland, Ohio) prepared by boiling and a double washing in isotonic saline, was resuspended in $\mathrm{PBS}, \mathrm{pH} 7.4$, containing $1 \mathrm{mM}$ $\mathrm{Mg}^{2+}$ and incubated with plasma at $37^{\circ} \mathrm{C}$ for $30 \mathrm{~min}$, in the ratio of $5 \mathrm{mg} / \mathrm{ml}$ plasma. Particulate zymosan was subsequently removed by centrifugation of activated plasma at $20,000 \mathrm{~g}$ for $10 \mathrm{~min}$ at $4^{\circ} \mathrm{C}$.

Total complement, $\mathrm{Cl}$, and $\mathrm{C} 3$ were determined by immune hemolysis as described above. Immunoelectrophoretic conversion of C3 and factor B was also assayed by the methods above. In addition, complement activation was assayed indirectly by the generation of chemotactic activity in cellophane-incubated plasma, utilizing a modi- 
fied Boyden chamber granulocyte chemotaxis system $(22,23)$. $0.2 \mathrm{ml}$ of normal granulocyte suspension $\left(10^{7}\right.$ cells $\left./ \mathrm{ml}\right)$, prepared by dextran sedimentation of heparinized whole blood, was added to the upper compartment of a Boyden chamber. Cellophane-incubated plasma was diluted to $2 \%$ (vol/vol) in Hank's balanced salt solution and $1.6 \mathrm{ml}$ added to the lower compartment, separated from the granulocyte compartment by a filter (Millipore Corp., Bedford, Mass.) with a $3-\mu \mathrm{m}$ mean pore size. Such a filter is of sufficient pore size to allow granulocyte, but not monocyte chemotaxis. Triplicate chambers were incubated in humidified air at $37^{\circ} \mathrm{C}$ for $2 \mathrm{~h}$, and the filters were then removed, washed, stained, and their distal sides counted. The chemotactic response was expressed as the number of segmented granulocytes seen in 10 grids $/ 10^{7}$ granulocytes applied to the upper compartment.

The capacity of cellophane-incubated plasma to induce granulocyte adhesion was measured in an in vitro system. Purified granulocytes were resuspended in the plasma under study. Duplicate $1-\mathrm{ml}$ aliquots of each suspension were added to $10 \times 35-\mathrm{mm}$ Petri dishes (Falcon Plastics, Division of BioQuest, Oxnard, Calif.), and incubated for $30 \mathrm{~min}$ at $37^{\circ} \mathrm{C}$. Nonadherent cells were removed by six washes with isotonic saline and the remaining, adherent granulocytes either counted directly with phase-contrast microscopy, or indirectly by assay of their myeloperoxidase content (24). Their myeloperoxidase content was expressed as a percentage of total granulocyte myeloperoxidase content initially applied to the Petri dish.

Rabbit studies. Adult New Zealand white rabbits were anesthetized with i.v. sodium pentothal USP, and pyrogenfree cannulae (Intracath, C. R. Bard Inc., Murray Hill, N. J.) were surgically inserted into the femoral vein and the femoral artery as far as the right atrium and aortic arch, respectively. Plasma was prepared, by the method described above, from blood drawn from the aortic cannula, and the unused erythrocytes were reinfused. After incubation with either cellophane or zymosan, and subsequent removal of the activator, the plasma was infused into the femoral vein cannula with a standard Harvard pump (Harvard Apparatus Co., Inc., Millis, Mass.). Automated blood cell counts and 200-cell, leukocyte differential counts were performed in duplicate upon EDTA-anticoagulated samples drawn simultaneously from both aortic and right atrial cannulae. Comparison of such simultaneous granulocyte counts provided an estimate of cell clearance by the pulmonary vasculature. During some plasma infusions, rapid pulmonectomy was performed. The resected lungs were examined by light microscopy after fixation in $10 \%$ formalin and staining with hematoxylin and eosin.

Before incubation with cellophane, some rabbit plasmas were heated at $56^{\circ} \mathrm{C}$ for $30 \mathrm{~min}$ (25), mixed with EDTA in a final concentration of $10 \mathrm{mM}(26)$, or incubated with $10 \mathrm{mM}$ hydrazine (27-29), to inhibit both classical and alternate pathways of the complement cascade. Relatively specific classical pathway inhibition was achieved by the addition of $10 \mathrm{mM}$ ethylene glycol tetraacetic acid (EGTA) containing $10 \mathrm{mM} \mathrm{Mg}^{2+}(30)$. Complement depletion was induced in vivo by the infusion of Naja-Naja cobra venom factor (CVF) (Ross Allen's Reptile Institute, Inc., Silver Springs, Fla.) purified by DEAE chromatography (31, 32). CVF activity was assayed against paroxysmal nocturnal hemoglobinuria erythrocytes $(33,23)$. Depletion of rabbit complement was induced by two i.v. 400-U CVF/kg injections, $24 \mathrm{~h}$ apart (31). Cellophane-incubated plasma infusion studies were performed in these animals 6-8 $\mathrm{h}$ after the last CVF injection, by which time the leukopenia induced by the CVF had resolved (34).

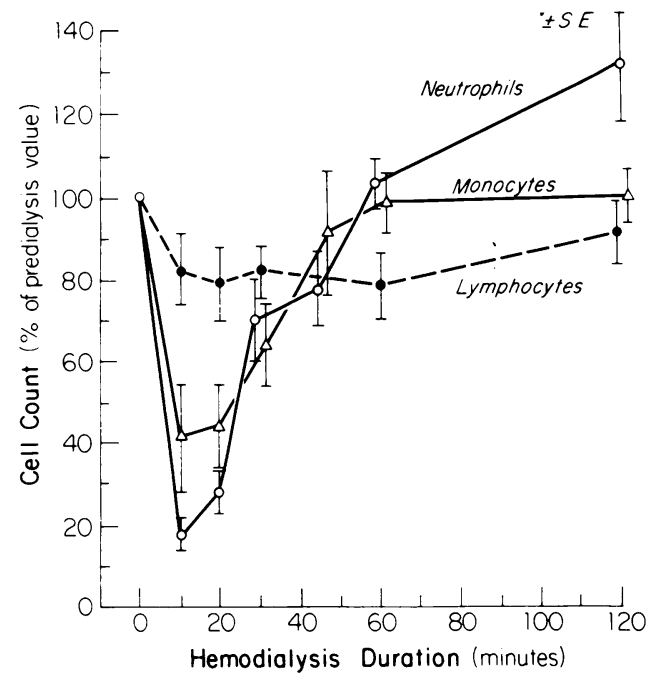

FIGURE 1 Neutrophil, monocyte, and lymphocyte counts, expressed as a percentage of their predialysis values, during the first $2 \mathrm{~h}$ of hemodialysis in 34 patients.

Cellophane- and zymosan-incubated plasmas were fractionated at $4^{\circ} \mathrm{C}$ with a Sephadex G-200 column $(2.5$ $\times 100 \mathrm{~cm}$, void volume $180 \mathrm{ml}$, and total bed volume 490 ml) using $\mathrm{PBS}$ at $\mathrm{pH} 7.4$ containing $0.001 \%$ sodium azide (wt/vol). $2 \mathrm{ml}$ of plasma was applied to the column, which had previously been calibrated with blue dextran, human hemoglobin, and cytochrome $c$, and the fractions eluting after void volume were pooled into eight sequential $50-\mathrm{ml}$ sets. Each set was infused individually into a cannulated rabbit at a $8-\mathrm{ml} / \mathrm{min}$ flow rate with 30 -min rest periods between each set. The arterial granulocyte count after a 2-min infusion was expressed as a percentage of the arterial count immediately before infusion, so that the approximate molecular weight of the most potent leukopenia-inducing fractions could be defined (35).

\section{RESULTS}

Patient studies. All 34 consecutive patients developed severe, albeit transient neutropenia $(P$ $<0.001$, paired $t$ test) and monocytopenia $(P<0.01)$ during the first $20 \mathrm{~min}$ of hemodialysis (Fig. 1). In contrast, decrements in the counts of the other cell types were marginal, as follows: lymphocytes 21 $\pm 38 \% \quad($ mean \pm SD $) \quad(P<0.05)$, platelets $6 \pm 25 \% \quad(P$ $>0.4)$, and erythrocytes $8 \pm 8 \%(P>0.2)$. Despite these changes in cell counts, there was no detectable increment in serum lysozyme levels; the predialysis level in 15 consecutive patients was $35.6 \pm 7.2 \mu \mathrm{g}$ egg-white lysozyme/ml (mean \pm SD) and the postdialysis level was $33.0 \pm 8.3 \mu \mathrm{g} / \mathrm{ml}$.

Immunoelectrophoretic analysis of serum from dialysis patients demonstrated the occurrence of complement activation (Figs. 2 and 3). C3 conversion was first apparent in serum from the efferent line of the dialyzer, within $10 \mathrm{~min}$ of institution of blood flow; at 20 min, conversion was evident in both afferent and 


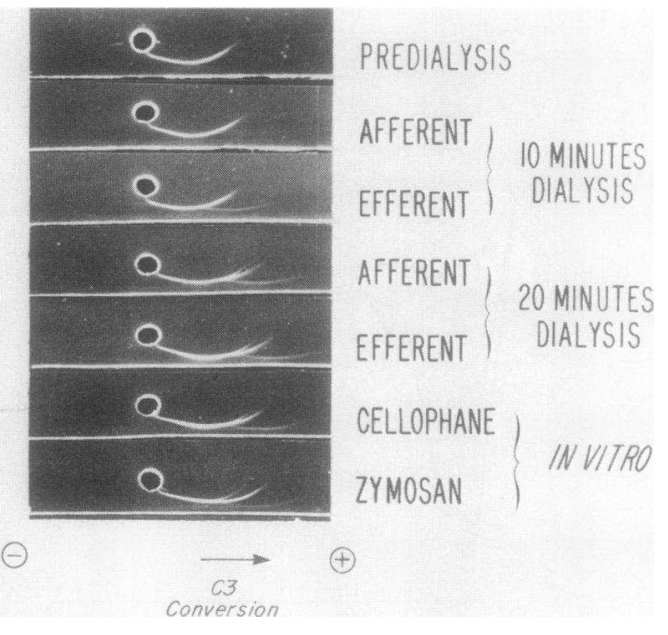

FIGURE 2 Immunoelectrophoretic analysis of C3 in sera from a dialyzed patient (upper five panels) and plasmas incubated in vitro with dialyzer cellophane and zymosan (lower two panels). Generation of anodal spurs indicates C3 activation.

efferent samples (top five patterns, Fig. 2). Such C3 conversion was detected in sera from eight consecutive dialysis patients. Low grade conversion of factor B was also evident in efferent sera after 10 and $20 \mathrm{~min}$ of dialysis (top three patterns, Fig. 3).

Experiments with human plasma in vitro. Incubation of human plasma with dialyzer cellophane produced a $25 \%$ decrement in serum total hemolytic complement, associated with preservation of hemolytic $\mathrm{C} 1$, but a significant decrement in hemolytic C3 (Fig. 4). Qualitatively similar changes were produced in plasma by incubation with zymosan, although, under the conditions of these experiments, complement depletion was more intense than with cellophane (Fig. 4). Immunodiffusion assays of C3 showed no reduction of $\mathrm{C} 3$ in cellophane-incubated plasma,

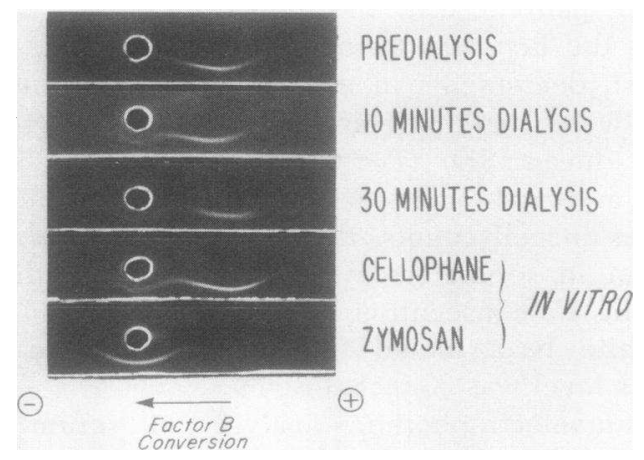

FIGURE 3 Immunoelectrophoretic analysis of factor B in sera from a dialyzed patient (upper three panels) and plasmas incubated in vitro with dialyzer cellophane and zymosan (lower two panels). Generation of arcs immediately below the wells indicates factor $B$ conversion.

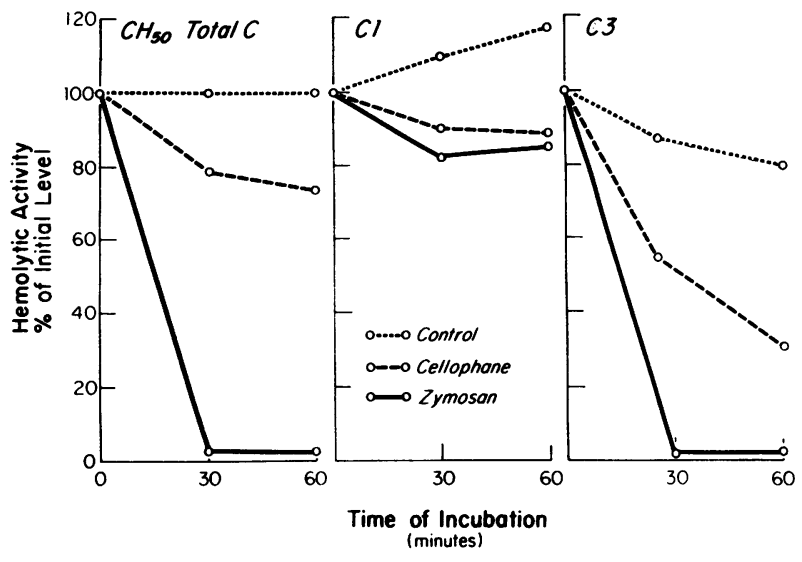

FIGURE 4 Total hemolytic complement, C1 and C3 levels, expressed as a percentage of initial values, during in vitro incubation of plasma with dialyzer cellophane and zymosan. Control plasmas were incubated alone. The depicted data are representive of those from five separate plasma incubations.

and a reduction of only $18 \%$ after treatment with zymosan. Immunoelectrophoresis of cellophane- and zymosan-incubated plasmas demonstrated conversion of C3 (lower two patterns, Fig. 2) and factor B (lower two patterns, Fig. 3). Not shown is the data that cellophane was also capable of inducing both $\mathrm{C} 3$ and factor $\mathrm{B}$ conversion in plasma from a patient with genetic deficiency of $\mathbf{C 2}$.

This in vitro complement depletion and conversion was accompanied by generation of factors with potent effects on the physical properties of granulocytes. Thus, cellophane-incubated plasma induced migration of $94 \pm 12($ mean \pm SD) polymorphonuclear leukocytes (PMN)/10 grids/107 PMN added to Boyden chambers; in contrast, control plasma incubated at $37^{\circ} \mathrm{C}$ in the absence of cellophane, induced the migration of only $35 \pm 7 \mathrm{PMN} / 10$ grids per $10^{7} \mathrm{PMN}(P$ $<0.005$, from three experiments). Moreover, both cellophane- and zymosan-incubated plasmas induced adhesion of normal human granulocytes to artificial plastic surfaces in vitro (Fig. 5). The effect of cellophane-incubated plasma was assayed by direct counting of adherent granulocytes (left, Fig. 5), and that of zymosan-incubated plasma by myeloperoxidase assay of adherent cells (right, Fig. 5). Adhesion was minimized when plasma was heated at $56^{\circ} \mathrm{C}$ for $30 \mathrm{~min}$ to inactivate complement, before incubation with cellophane or zymosan (stippled bars, Fig. 5).

Rabbit studies. Infusion of autologous, cellophane-incubated rabbit plasma into the vena cava at the rate of $1 \mathrm{ml} / \mathrm{min}$, induced selective monocytopenia (not shown) and neutropenia, but no significant decrement in lymphocyte counts (Fig. 6). At this infusion rate, the decrement in granulocyte counts across the 
cardiopulmonary circulation was $24 \pm 10 \%$ (mean \pm SD of four experiments). Increase in infusion rate to 10 $\mathrm{ml} / \mathrm{min}$ resulted in a more severe neutropenia with $96 \pm 4 \%$ decrements in granulocyte count, and an increase in clearance of cells by the cardiopulmonary circulation to $85 \pm 15 \%$. At both flow rates this arteriovenous difference in cell counts (sampled from the right atrium and aortic arch) reversed after cessation of infusion, consistent with the return of granulocytes to the systemic circulation from their site of sequestration within the lung vasculature.

The occurrence of pulmonary leukostasis was further confirmed histologically. Infusion of cellophaneincubated plasma resulted in engorgement with segmented granulocytes of small vessels, including arterioles, venules, and capillaries (Fig. 7a). Infusion of cellophane-incubated plasma, which had been previously heated at $56^{\circ} \mathrm{C}$ for $30 \mathrm{~min}$ to prevent $\mathrm{C}$ activation, produced no leukostasis (Fig. $7 b$ ). In animals infused with active plasma, serum lysozyme levels did not increase during granulocyte and monocyte sequestration. Thus, at the end of a 20 -min cellophane-incubated plasma infusion ( $1 \mathrm{ml} / \mathrm{min}$ ), the aortic and vena cava serum lysozyme levels were respectively $1.75 \pm 0.61$ and $1.74 \pm 0.54 \mu \mathrm{g} / \mathrm{ml}$, not significantly different from each other or increased above the preinfusion levels of $1.78 \pm 0.62$ and 1.98 $\pm 0.61 \mu \mathrm{g} / \mathrm{ml}$. It is therefore unlikely that leukostasis is accompanied by significant lysozyme release. The capacity of dialyzer cellophane to induce plasma
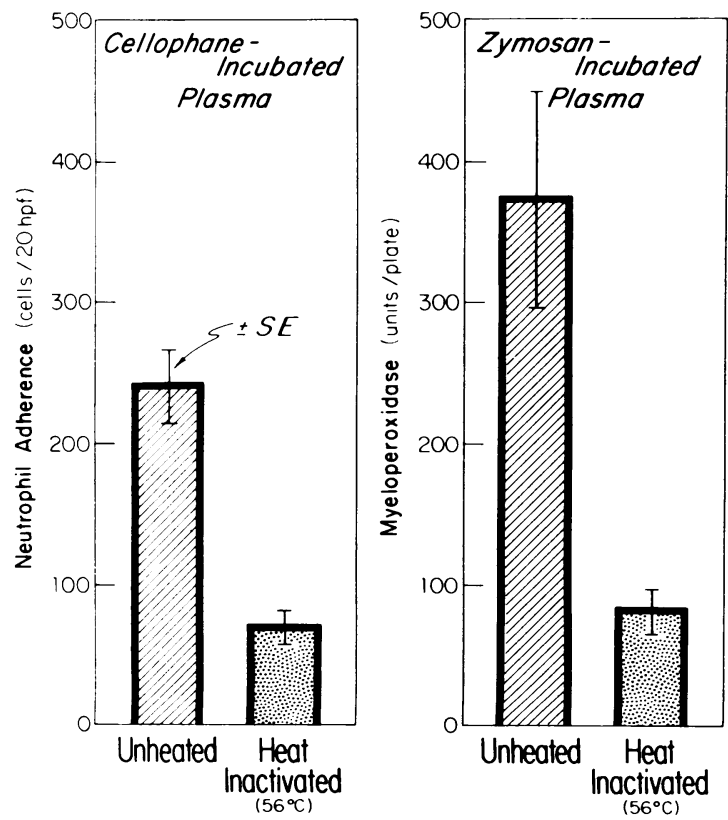

FIGURE 5 Granulocyte adherence to plastic surfaces induced by cellophane-incubated plasma (left), and zymosanincubated plasma (right).

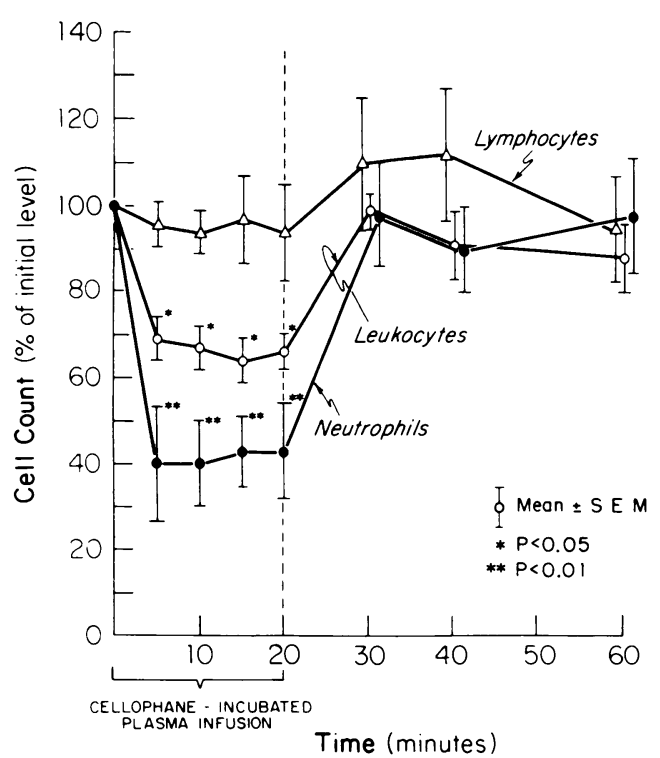

Figure 6 Total leukocyte, neutrophil, and lymphocyte counts in rabbits infused with autologous, cellophane-incubated plasma at the rate of $1 \mathrm{ml} / \mathrm{min}$. $P$ values are derived from the paired $t$ test.

activation and subsequent leukopenia was not inhibited by four washes in isotonic saline or distilled water, nor by boiling or incubation with albumin at $37^{\circ} \mathrm{C}$ for $30 \mathrm{~min}$.

When reinfused into rabbits not only did dialyzer cellophane-activated plasma induce neutropenia (solid circles, Fig. 8), but infusion of plasma in which $\mathrm{C}$ was activated by zymosan incubation also produced similar, albeit more prolonged, decrement in neutrophil counts (open triangles, Fig. 8). Addition of $10 \mathrm{mM}$ EDTA to plasma before cellophane incubation prevented neutropenia (squares, Fig. 8), whereas $10 \mathrm{mM}$ EGTA/ $\mathrm{Mg}^{2+}$ (which preserves alternative pathway activation) was noninhibitory (open circles, Fig. 8). Moreover, heated or hydrazine-treated plasmas were separately inactive after cellophane incubation, but if they were mixed before cellophane exposure (thereby reconstituting C3 activatability) neutropenia-inducing activity was regained (not shown). Finally, reinfusion of plasma which had been decomplemented by injecting the donor rabbit with two doses of CVF was incable of inducing neutropenia; in contrast complement-replete plasma, collected before the CVF infusions, produced the expected leukopenia both in normal and in CVF-treated rabbits (not shown).

When fractions of cellophane- or zymosan-incubated plasmas were prepared by Sephadex G-200 filtration and reinfused into rabbits, the most marked neutropenia was induced with fractions of the approximate molecular weight range of 7,000-20,000 daltons (eluate volume 420-520 ml, Fig. 9). 


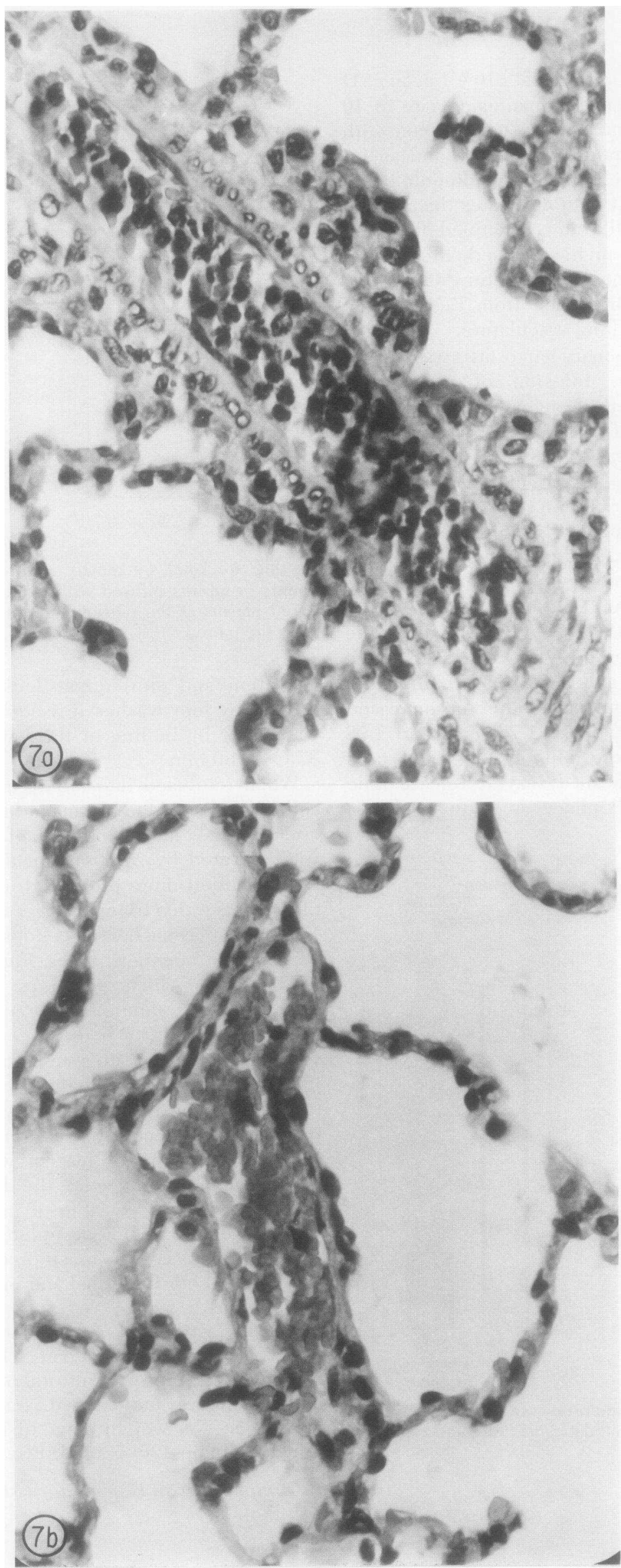




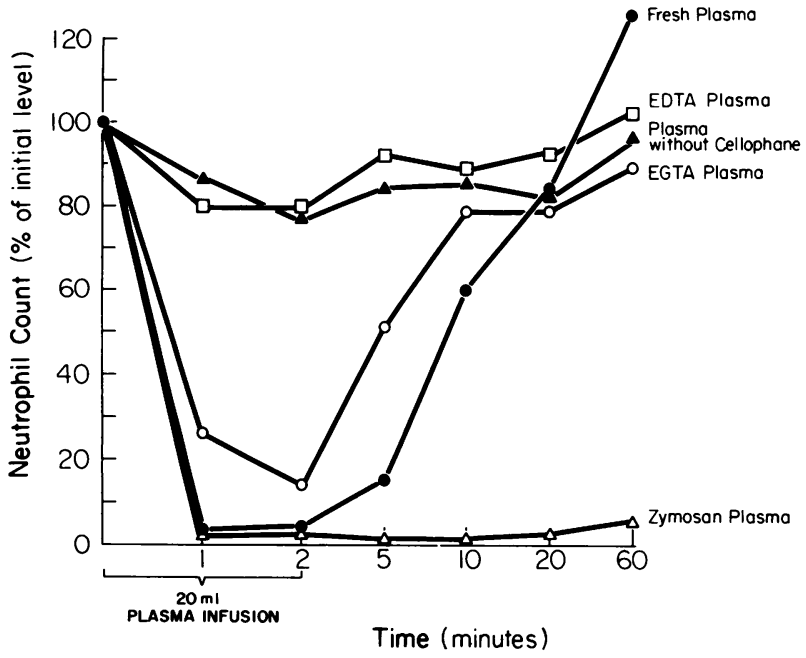

FIGURE 8 The neutropenia induced by infusion of fresh plasma after cellophane incubation (O), is obviated by failure to add cellophane to the incubating plasma $(\Delta)$, or by prior addition of $10 \mathrm{mM}$ EDTA $(\square)$, preserved despite prior addition of $10 \mathrm{mM}$ EGTA/Mg ${ }^{2+}(O)$, and duplicated by infusion of zymosan-incubated plasma $(\triangle)$.

\section{DISCUSSION}

Hemodialysis has been in clinical use for many years (36), but some of its diverse and unsuspected complications have only recently become apparent $(37,38)$. The acute leukopenia of hemodialysis was described 8 yr ago $(1,2)$, but its mechanism has remained obscure (39). Entrapment of granulocytes within the dialyzer was initially proposed (40), but cell kinetic studies demonstrated sequestration within the patient's microcirculation (2), which was subsequently confirmed in dialyzed dogs where the lung was the primary site of accumulation (4). The present studies demonstrate that dialyzer cellophane activates complement during human hemodialyses. Moreover, from our ancillary studies in rabbits it appears that low molecular weight ( $\cong 7,000-20,000$ daltons) $C$ components generated by exposure of plasma to dialyzer cellophane can induce sequestration of granulocytes and monocytes within the pulmonary vasculature when infused into the venous circulation. Combining these data, we suggest that these same activated C components produce pulmonary leukostasis in hemodialyzed humans as well, and in studies to be published elsewhere, we demonstrate that such leukostasis produces significant pulmonary dysfunction in these patients.
The conversion of factor B by cellophane in vivo and in vitro implicates significant participation of the alternative pathway in this complement activation. Indeed, immunoelectrophoresis conversion of both C3 and factor B was demonstrated after incubation of cellophane, not only with normal, but also with C2-deficient plasma. Our studies do not exclude the possibility that cellophane might also activate the classical pathway, and it should be noted that zymosan, although a potent activator of the alternative pathway, is also able to activate the classical pathway, along with several other, high molecular weight polysaccharides (41). Nevertheless, alternative pathway activation is probably predominant, since, at least in vitro, cellophane induced C3 activation in C2deficient plasma and caused depletion of C3 while sparing C1 (Fig. 4); this C3 depletion cannot be explained by simple binding of $\mathrm{C} 3$ to cellophane because the $\mathrm{C} 3$ depletion as assayed by EAC1,4,2 hemolysis greatly exceeded that defined by the immunodiffusion assay. Moreover, the maintenance of cellophane-induced neutropenia in EGTA-, but not EDTA-, containing plasmas also suggests that alternative pathway activation is importantly involved in our findings.

Although more rigorous analysis is required, the present data suggest that if indeed an activated complement product is responsible for the leukopenia/ pulmonary leukostasis phenomena, it has a molecular weight in the range of 7,000-20,000 daltons. In similar studies of the neutropenia which results from i.v. infusion of $\mathrm{CVF}$, McCall and co-workers were able to define factor(s) of identical size range as being responsible for the cytopenia, and postulated that this factor may be derived from either C3 or C5 (34). C5a has a molecular weight of 17,000 daltons (42), and is able to alter the surface charge of granulocyte plasma membranes (10), induce granulocyte chemotaxis (8), and release lysosomal enzymes from cytochalasin B-treated granulocytes (11). Nevertheless, C3a, with the molecular weight of 9,000 daltons (42), although less potent that C5a, is probably also able to induce granulocyte chemotaxis (7-9), and, on the basis of the present data, cannot be excluded as the factor responsible for leukostasis.

Although we suggest that i.v. infusion of such a factor(s) induces pulmonary leukostasis, it is not certain whether granulocyte aggregation, followed by pulmonary embolism of the aggregates, is the pri-

FIGURE 7 Sections of rabbit lungs resected during infusion of cellophane-incubated plasma demonstrate engorgement of vessels with leukocytes $(a)$. In contrast cellophane-incubated plasma in which complement had been inactivated by heating at $56^{\circ} \mathrm{C}$ for 30 min induces no leukostasis - only red cells being present in pulmonary vessels $(b)$. ( $\times 600$ magnification) 

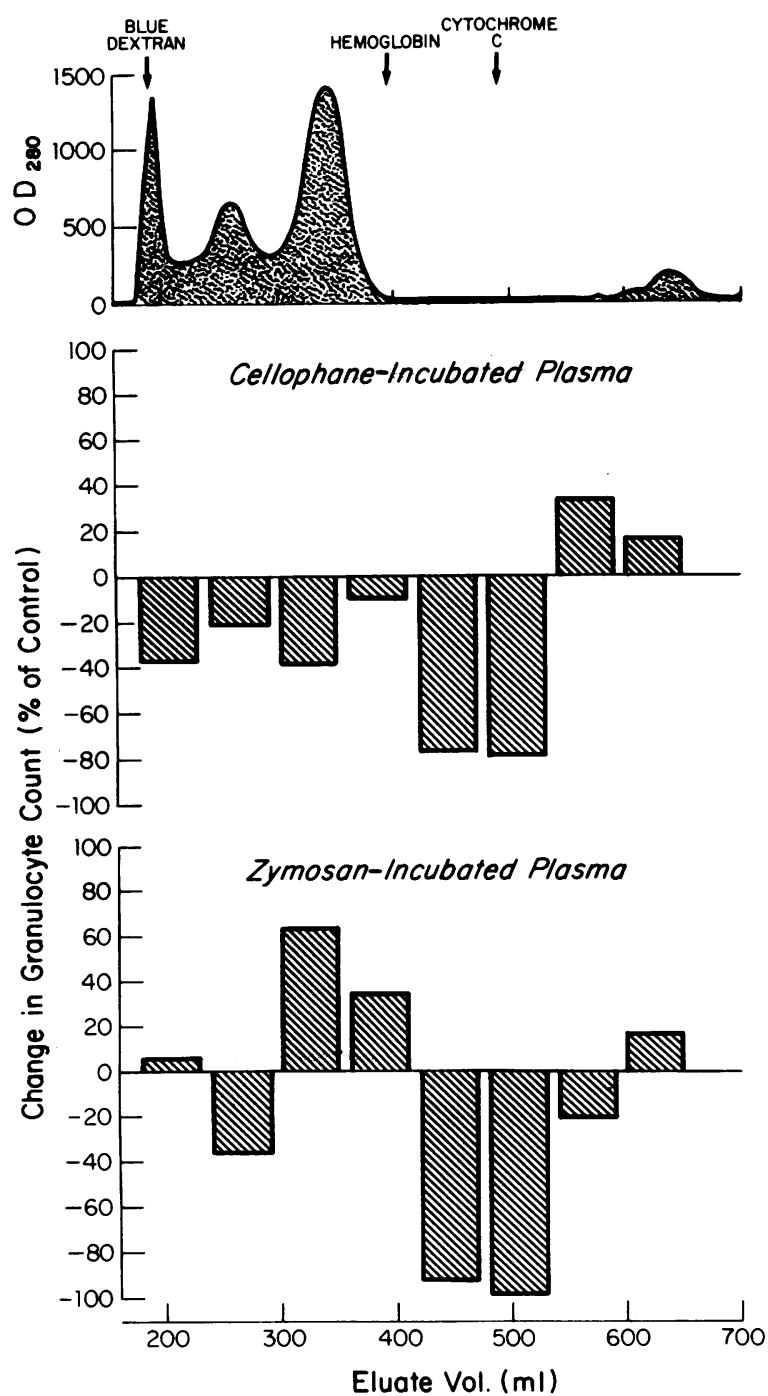

Figure 9 Sephadex G-200 chromatography of rabbit plasmas. Protein concentration $\left(O D_{280 \mathrm{~nm}}\right)$ and calibration points are depicted in the upper panel. The acute changes in granulocyte count induced by infusion of each of the eight pooled fractions are depicted for cellophane-incubated (center panel) and zymosan-incubated (lower panel) plasmas (from one of three experiments). Most pronounced granulocytopenia was induced by fractions eluting between 420 $520 \mathrm{ml}$, with an estimated molecular weight of 7,000-20,000 daltons.

mary event, or whether the factor primarily coats the pulmonary endothelium, trapping the cells as they flow by. Although when initially contemplated, the rapidity of onset of neutropenia seemed to us more consistent with the latter mechanism, our more recent studies demonstrate that granulocytes indeed aggregate when exposed to C5a, and do so within $20 \mathrm{~s}$, at least in vitro (43). Thus, granulocyte aggregation and pulmonary embolization remain a viable potential mechanism for hemodialysis pulmonary injury.
The absence of any detectable increase in serum lysozyme during leukostasis in patient or rabbits implies that the complement/granulocyte interaction of dialysis is not accompanied by prominent degranulation. Indeed, if C5a proves to be causal to the leukostasis syndrome, it is noteworthy that this component will only induce appreciable lysosomal enzyme release if granulocytes are first rendered labile with cytochalasin B (11).

The transience of leukopenia during hemodialysis may well result from progressive inability during the procedure of the cellophane membranes to activate complement. It is known that reuse of a dialyzer will not result in leukopenia unless it is thoroughly rinsed with isotonic saline (44), suggesting that the cellophane becomes coated with salinesoluble agent(s) which block its activating capacity but not its efficacy as a dialyzer component.

These data not only suggest an explanation for the phenomenon of hemodialysis leukopenia and leukostasis, but may also generate insights into the abnormalities of peripheral granulocyte counts in other clinical situations. For instance, we suggest that the chronic granulocytopenia seen in patients with ongoing complement activation, such as occurs in Felty's syndrome or in systemic lupus erythematosus (45), may be of similar origin, particularly in those patients with undetectable leukoagglutinins (46).

\section{ACKNOWLEDGMENTS}

The authors wish to thank Drs. Carl M. Kjellstrand and T. J. Buselmeier, and the Staff of the Hemodialysis Unit, University of Minnesota Hospitals for their cooperation, and Miss Georgia Huard and Mrs. Anne Koeune for their excellent technical assistance.

This work was supported by U. S. Public Health Service grants CA15627, HL15215, HL18210, AM15730, and HL19725, and grants from the Minnesota Medical Foundation, the University of Minnesota Graduate School, the Parker B. Francis Foundation and the Veterans Administration.

\section{REFERENCES}

1. Kaplow, L. S., and J. A. Goffinet. 1968. Profound neutropenia during the early phase of hemodialysis. J. Am. Med. Assoc. 203: 1135-1137.

2. Gral, T., P. Schroth, J. R. DePalma, and A. Gordon 1969. Leukocyte dynamics with three types of hemodialyzers. Trans. Am. Soc. Artif. Intern. Organs. 15: 45-49.

3. Brubaker, L. H., and K. D. Nolph. 1971. Mechanisms of recovery from neutropenia by hemodialysis. Blood. 38: $623-631$.

4. Toren, M., J. A. Goffinet, and L. S. Kaplow. 1970. Pulmonary bed sequestration of neutrophils during hemodialysis. Blood. 36: 337-340.

5. Henderson, L. W., M. E. Miller, R. W. Hamilton, and M. E. Norman. 1975. Hemodialysis leukopenia and polymorph random mobility-a possible correlation. J. Lab. Clin. Med. 85: 191-197. 
6. Jensen, D. P., L. H. Brubaker, K. D. Nolph, C. A. Johnson, and R. J. Nothum. 1973. Hemodialysis coilinduced transient neutropenia and overshoot neutrophilia in normal man. Blood. 41: 399-408.

7. Ward, P. A. 1967. A plasmin-split fragment of $\mathrm{C}^{\prime} 3$ as a new chemotactic factor. J. Exp. Med. 126: 189-206.

8. Snyderman, R., H. Gewurz, and S. E. Mergenhagen. 1968. Interactions of the complement system with endotoxic polysaccharide. Generation of a factor chemotactic for polymorphonuclear leukocytes. J. Exp. Med. 128: 259-275.

9. Ward, P. A., C. G. Cochrane, and H. J. Muller-Eberhard. 1966. Further studies on the chemotactic factor of complement and its formation in vivo. Immunology. 11: $141-153$.

10. Gallin, J. I., J. R. Durocher, and A. P. Kaplan. 1975. Interaction of leukocyte chemotactic factors with the cell surface. Chemotactic factor-induced changes in human granulocyte surface charge. J. Clin. Invest. 55: 967974.

11. Goldstein, I., S. Hoffstein, J. Gallin, and G. Weissmann. 1973. Mechanisms of lysosomal enzyme release from human leukocytes: Microtubule assembly and membrane fusion induced by a component of complement. Proc. Natl. Acad. Sci. U. S. A. 70: 2916-2920.

12. Goldstein, I. M., M. Bral, A. G. Osler, and G. Weissmann. 1973. Lysosomal enzyme release from human leukocytes: Mediation by the alternate pathway of complement activation. J. Immunol. 111: 33-37.

13. Snyderman, R., and M. C. Pike. 1975. Interactions of complex polysaccharides with the complement system. Effect of calcium depletion on terminal component consumption. Infect. Immun. 11: 273-279.

14. Quinton, W., D. Dillard, and B. H. Scribner. 1960. Cannulation of blood vessels for prolonged hemodialysis. Trans. Am. Soc. Artif. Intern. Organs. 6: 104109.

15. Buselmeier, T. J., C. M. Kjellstrand, E. A. Santiago, R. L. Simmons, and J. S. Najarian. 1973. A new subcutaneous arteriovenous shunt: Applicable in cases where the standard Quinton-Scribner shunt and arteriovenous fistula have failed. Surgery (St. Louis). 73: 512-520.

16. Brescia, M. J., J. E. Cimino, K. Appel, and B. J. Hurwich. 1966. Chronic hemodialysis using venipuncture and a surgically created arteriovenous fistula. N. Engl. J. Med. 275: 1089-1092.

17. Kjellstrand, C-M., and T. J. Buselmeier. 1972. A simple method for anticoagulation during pre- and postoperative hemodialysis avoiding rebound phenomenon. Surgery (St. Louis). 72: 630-633.

18. Kabat, E. A., and M. M. Mayer. 1961. Experimental Immunochemistry. 2nd edition. Charles C Thomas, Publisher, Springfield, Ill. 135-139.

19. Nelson, R. A., Jr., J. Jensen, I. Gigli, and N. Tamura. 1966. Methods for the separation, purification and measurement of nine components of hemolytic complement in guinea-pig serum. Immunochemistry. 3: 111135.

20. Vroon, D. H., D. R. Schultz, and R. M. Zarco. 1970. The separation of nine components and two inactivators of components of complement in human serum. Immunochemistry. 7: 43-61.

21. Müller-Eberhard, H. J., A. P. Dalmasso, and M. A. Calcott. 1966. The reaction mechanism of $\beta$ lc-globulin $\left(C^{\prime} 3\right)$ in immune hemolysis. J. Exp. Med. 123: 33-54.

22. Boyden, S. 1962. The chemotactic effect of mixtures of antibody and antigen on polymorphonuclear leukocytes. J. Exp. Med. 115: 453-466.

23. Craddock, P. R., J. Fehr, and H. S. Jacob. 1976. Complement-mediated granulocyte dysfunction in paroxysmal nocturnal hemoglobinuria. Blood. 47: 931-939.

24. Paul, B. B., R. R. Shauss, A. A. Jacobs, and A. J. Sbarra. 1970. Function of $\mathrm{H}_{2} \mathrm{O}_{2}$, myeloperoxidase, and hexose monophosphate shunt enzymes in phagocytizing cells from different species. Infect. Immun. 1: 338-344.

25. Kabat, E. A., and M. M. Mayer. 1961. Experimental Immunochemistry. Charles C. Thomas, Publisher, Springfield, Ill. 2nd edition. 159-161.

26. Frank, M. M., H. J. Rapp, and T. Borsos. 1964. Studies on the terminal steps of immune hemolysis. I. Inhibition by trisodium ethylenediaminetetraacetate (EDTA). J. Immunol. 93: 409-413.

27. Ruddy, S., I. Gigli, and K. F. Austen. 1972. Complement system of man (first of four parts). N. Engl. J. Med. 287: 489-495.

28. Pillemer, L., J. Seifter, and E. E. Ecker. 1941. The effect of amino compounds on the fourth component of complement. J. Immunol. 40: 89-95.

29. Pensky, J., L. Wurz, L. Pillemer, and H. Lepow. 1959. The properdin system and immunity XXI. Assay, properties and partial purification of a hydrazine-sensitive serum factor (factor A) in the properdin system. Z. Immunitaetsforsch. Exp. Ther. 118: 329-348.

30. Fine, D. P., S. R. Marney, Jr., D. G. Colley, J. S. Sergent, and R. M. Des Prez. 1972. C3 shunt activation in human serum chelated with EGTA. J. Immunol. 109: 807-809.

31. Cochrane, C. G., H. J. Müller-Eberhard, and B. S. Aikin. 1970. Depletion of plasma complement in vivo by a protein of cobra venom: Its effect on various immunologic reactions. J. Immunol. 105: 55-69.

32. Ballow, M., and C. G. Cochrane. 1969. Two anticomplementary factors in cobra venom: Hemolysis of guinea pig erythrocytes by one of them. J. Immunol. 103: 944-952.

33. Kabakci, R., W. F. Rosse, and G. L. Logue. 1972. The lysis of paroxysmal nocturnal haemoglobinuria red cells by serum and cobra factor. Br. J. Haematol. 23: 693-705.

34. McCall, C. E., L. R. deChatelet, D. Brown, and P. Lachmann. 1974. New biological activity following intravascular activation of the complement cascade. Nature (Lond.). 249: 841-843.

35. Andrews, P. 1964. Estimation of the molecular weights of proteins by Sephadex gel-filtration. Biochem. J. 91: $222-233$

36. Wolf, A. V., D. G. Remp, J. E. Kiley, and G. D. Currie. 1951. Artificial kidney function: kinetics of hemodialysis. J. Clin. Invest. 30: 1062-1070.

37. Conger, J. D., W. S. Hammond, A. C. Alfrey, S. R. Contiguglia, R. E. Stanford, and W. E. Huffer. 1975. Pulmonary calcification in chronic dialysis patients. Clinical and pathologic studies. Ann. Intern. Med. 83: 330-336.

38. Lindner, A., B. Charra, D. J. Sherrard, and B. H Scribner. 1974. Accelerated atherosclerosis in prolonged maintenance hemodialysis. N. Engl. J. Med. 290: 697701.

39. Hempers, C. L., E. Schupak, E. G. Lowrie, and J. M. Lazarus. 1973. Long-term Hemodialysis. Grune \& Stratton, Inc., New York. 2nd edition. 125-127.

40. Brubaker, L. H., D. Jensen, C. Johnson, R. Nothum, and K. Nolph. 1972. Kinetics of stagnation-induced neutropenia during hemodialysis. Trans. Am. Soc. Artif. Intern. Organs. 18: 305-311. 
41. Osler, A. G. 1976. Complement. Mechanisms and Functions. Prentice-Hall, Inc., Englewood Cliffs, N. J. 41-42.

42. Vallota, E. H., and H. J. Müller-Eberhard. 1973. Formation of C3a and C5a anaphylotoxins in whole human serum after inhibition of the anaphylotoxin inactivator. J. Exp. Med. 137: 1109-1123.

43. Craddock, P. R., D. E. Hammerschmidt, J. G. White, and H. S. Jacob. 1976. Granulocyte (PMN) aggregometry, a new technique for the study of $\mathrm{PMN} /$ complement (C) interaction in vitro. Clin. Res. 24: 540A. (Abstr.)

44. Gral, T., P. Schroth, J. R. DePalma, and M. H. Maxwell.
1969. Leukocyte dynamics during haemodialysis. In Dialysis and Renal Transplantation. D. N. S. Kerr, editor. Pitman Medical Publishing Co., Ltd. London, England. XI: 312-318.

45. Copeland, G. D., D. von Capeller, and T. N. Stern. 1958. Systemic lupus erythematosus: A clinical report of 47 cases with pathologic findings in 18. Am. J. Med. Sci. 236: 318-329.

46. Finch, S. C. 1972. Granulocytopenia. In Hematology. W. J. Williams, E. Beutler, A. J. Erslev, and R. WayneRundles, editors. McGraw-Hill, Inc., New York. 628654. 